\title{
Optimalisasi Fasilitas Gudang CFS (Container Freight Station) Terhadap Proses Behandle di PT. Terminal Teluk Lamong Surabaya
}

\author{
Dian Utari Maharani ${ }^{\mathrm{a}}$, Andy Wahyu Hermanto ${ }^{\mathrm{b}}$

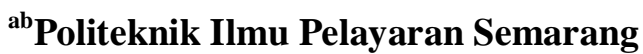 \\ a'Email: dianutarimahar@gmail.com \\ ${ }^{\mathrm{b}}$ Email: andy120605@gmail.com
}

\begin{abstract}
ABSTRAK
Gudang CFS dapat dioptimalisasikan untuk kegiatan stripping stuffing barang petikemas LCL, namun karena PT. Terminal Teluk Lamong ingin menekan angka Dwelling Time sehingga kegiatan stripping stuffing petikemas LCL tidak dilakukan digudang CFS. Kemudian karena tidak adanya kegiatan di Gudang CFS, maka PT. Terminal Teluk Lamong memanfaatkan Gudang CFS untuk kegiatan pemeriksaan fisik peti kemas (behandle). Penelitian ini bertujuan untuk mengetahui fasilitas Gudang CFS dapat menunjang proses behandle, mengetahui faktor faktor yang memengaruhi proses behandle, serta mengetahui upaya yang dapat dilakukan guna mengatasi keterbatasan fasilitas Gudang CFS saat proses behandle berlangsung.

Peneliti menggunakan metode deskriptif kualitatif untuk menggambarkan dan menguraikan objek yang diteliti. Peneliti terlibat dalam proses pencarian data dengan mengamati dan menganalisa fakta dan karakteristik objek dan subjek yang diteliti secara langsung. Sumber data yang digunakan dalam penelitian ini adalah data primer dan sekunder. Selain itu, penelitian ini juga menggunakan metode pengumpulan data dengan cara observasi, wawancara, dokumentasi, studi kepustakaan. Peneliti menggunakan observasi langsung dan tidak langsung. Hasil penelitian menyimpulkan bahwa fasilitas Gudang CFS dapat digunakan untuk menunjang proses behandle di PT. Terminal Teluk Lamong Surabaya. Akan tetapi pemeriksaan fisik tidak sepenuhnya dilakukan diarea gudang karena desain bangunan gudang yang tidak cocok untuk kegiatan pemeriksaan, sehingga kegiatan behandle dilakukan di luar area gudang dan baru memasukkan muatan ke dalam gudang dengan alat bantu forklift. Faktor yang menghambat kegiatan behandle antara lain: Faktor Internal \& Faktor Eksternal. Upaya yang dapat dilakukan guna mengoptimalkan kegiatan behandle yaitu dengan cara merenovasi gudang, mempersiapkan sarana pendukung untuk pemeriksaan barang, serta mempersiapkan SDM yang kompeten.
\end{abstract}

Kata Kunci: Fasilitas, Behandle, Gudang

\section{PENDAHULUAN}

Indonesia merupakan negara yang memiliki keadaan geografis berupa kepulauan, sehingga dalam melakukan kegiatan ekspor impor biasanya para eksportir dan importir dari Indonesia memilih sarana transportasi melalui jalur laut untuk mendistribusikan barangnya. Dalam kegiatan ekspor impor, terdiri dari berbagai jenis barang yang melintasi pelabuhan oleh karena itu harus dilakukan penanganan yang khusus agar barang tersebut tidak rusak pada saat dipindahkan dari kapal ke dermaga lalu ke lapangan penumpukan atau ke gudang begitupun sebaliknya. Untuk menunjang kegiatan ekspor dan impor di Indonesia harus memiliki sarana dan prasarana yang memadai untuk mendukung kegiatan ekspor impor tersebut.
PT. Terminal Teluk Lamong adalah anak perusahaan dari PT. Pelabuhan Indonesia III (Persero) yang dibangun sebagai pengembangan dari pelabuhan Tanjung Perak Surabaya yang dilengkapi dengan perlatan semi-otomatis berbasis ramah lingkungan. PT. Terminal Teluk Lamong di jadikan sebagai solusi terbaik untuk memecah kepadatan dan mempercepat proses penyebaran arus barang khususnya dari dan ke wilayah Kawasan Timur Indonesia. Terminal Teluk Lamong merupakan terminal semi otomatis pertama di Indonesia. Tidak hanya sebagai pelabuhan yang modern dan berkinerja tinggi, Terminal Teluk Lamong menjadi pelabuhan green port pertama di Indonesia.

PT. Terminal Teluk Lamong melayani jasa bongkar muat petikemas dan curah kering. Dengan tersedianya peralatan modern, Terminal 
Teluk Lamong diharapkan secara luas mampu menggerakkan serta mendorong perekonomian di Indonesia. Tujuan dibangunnya Terminal Teluk Lamong adalah meningkatkan Safety, Productivity, dan market share yang selama ini dirasakan masih kurang dan bahkan belum terdapat di pelabuhan pelabuhan beserta terminal seluruh Indonesia.

Dermaga, Container Yard, Container Freight Station, Transfer Area, Gate dan lainnya, merupakan fasilitas yang dimiliki oleh PT. Terminal Teluk Lamong. Container Freight Station merupakan gudang yang disiapkan oleh Terminal Petikemas untuk mengkonsolidasi barang atau muatan muatan. Didalam gudang CFS dilakukan proses Stuffing (Pengeluaran) barang dari petikemas dan proses Stripping (Pemuatan) barang kedalam petikemas.

PT. Terminal Teluk Lamong memiliki gudang CFS dengan total luas $5000 \mathrm{~m} 2$, gudang di CFS ini awalnya difungsikan untuk tempat pengkonsolidasiaan petikemas LCL, namun karena disekitaran area PT. Terminal Teluk Lamong terdapat depo-depo petikemas serta untuk menekan angka Dwelling Time sehingga gudang CFS(Container Freight Station) tidak lagi dialihfungsikan untuk kegiatan pengkonsolidasian petikemas LCL. Dwelling Time merupakan waktu yang dihitung mulai dari suatu peti kemas di bongkar dan diangkat dari kapal sampai petikemas tersebut meninggalkan terminal melalui pintu utama.

Sehingga gudang CFS di PT. Terminal Teluk Lalong sekarang dimanfaatkan atau dialihfungsikan untuk kegiatan behandle. Kegiatan behandle merupakan kegiatan pemeriksaan terhadap petikemas import yang dicurigai oleh Bea Cukai. Ketika pemilik barang terkena SPJM (Surat Pemberitahuan Jalur Merah) maka petikemas tersebut harus dicek fisik atau behandle, kegiatan behandle ini dilakukan di area Gudang CFS.

Pemeriksaan fisik tidak sepenuhnya dilakukan diarea gudang karena desain bangunan gudang tidak cocok untuk kegiatan pemeriksaan, sehingga kegiatan behandle dilakukan diluar area gudang dan baru memasukkan muatan ke dalam gudang dengan alat bantu forklift. Sehingga jika pemeriksaan dilakukan diluar banyak faktor yang menghambat kegiatan pemeriksaan petikemas.Untuk kegiatan behandle yang memanfaatkan gudang CFS sebenarnya bisa dilakukan dengan catatan sarana dan prasarana yang memadai, dilihat dari uraian diatas masih banyak faktor yang memengaruhi kegiatan behandle. Sehingga terminal sebagai penyedia jasa fasilitas harus mempersiapkan seluruh sarana dan prasarana yang baik agar kegiatan behandle di Terminal Teluk Lamong dapat berjalan dengan baik.

Berdasarkan pada latar belakang masalah di atas, maka tujuan penelitian ini adalah untuk mengetahui optimalisasi gudang CFS (Container Freight Station) di PT. Terminal Teluk Lamong Surabaya pada proses kegiatan behandle dan untuk mengetahui faktor-faktor yang mempengaruhi kegiatan behandle di PT. Terminal Teluk Lamong Surabaya.

\section{METODE}

Penelitian ini dilakukan di PT. Terminal Teluk Lamong Surabaya yang beralamatkan di Jalan Raya Tambak Osowilangon KM 12 Surabaya 60191 terhitung dari tanggal 17 Juni 2019 sampai dengan 29 Juli 2019.

Sumber data dalam penelitian ini adalah dari mana data diperoleh atau semua informasi baik yang merupakan benda nyata, sesuatu yang abstrak, maupun peristiwa yang terjadi pada waktu melakukan penelitian di PT. Terminal Teluk Lamong Surabaya. Jenis data yang dikumpulkan dalam penelitiaan ini adalah:

a) Data Primer dengan melakukan wawancara kepada Bapak Doni Rastio Prayogi selaku Dry Bulk and LNG sptd, Ibu Lisa Ayu Agdiana selaku CFS Admin, dan Bapak Gufron Khafid selaku Shift Manager karena beliau merupakan orang yang terlibat secara langsung dalam kegiatan yang berada didalam Gudang CFS (Container Freight Station) untuk memperlancar proses behandle di PT. Terminal Teluk Lamong Surabaya.

b) Data Sekunder melalui buku-buku yang membahas tentang kegiataan behandle atau melalui literatur-literatur yang berkaitan dengan objek yang diteliti.

Metode Pengumpulan Data yang digunakan dalam penelitian ini, yaitu: wawancara, observasi, dan studi pustaka. Sedangkan teknik analisis data dilakukan dalam 
tiga tahapan yaitu reduksi data, penyajiaan data dan penarikan kesimpulan.

Reduksi data dalam hal ini adalah cara menginformasikan teori dalam seperangkat konsep yang tinggi tingkatan abstraksinya atas dasar keseragaman dari seperangkat kategori. Data yang ada dipelajari dan dilakukan pembatasan teori sehingga menjadi padat dan berisi dengan mengeluarkan data yang tidak relevan, mengintegrasikan hal-hal yang kecil ke dalam kerangka kategori yang berkaitan.

Penyajian data dilakukan dengan mengelompokkan responden dan perilakunya, serta bagaimana perbedaannya sehingga dapat menemukan tema dan pembentukan hipotesis yang dibuat dengan cepat.

Kesimpulan dari penelitian ini dapat digunakan sebagai referensi bagi PT. Terminal Teluk Lamong Surabaya untuk meningkatkan fasilitas yang ada di dalam gudang CFS sehingga kegiataan behandle dapat terpenuhi.

\section{HASIL DAN PEMBAHASAN}

PT. Terminal Teluk Lamong merupakan perusahaan jasa kepelabuhanan yang menyediakan jasa operator terminal petikemas (Internasional dan Domestik) dan curah kering dengan standar pangan. PT. Terminal Teluk Lamong sendiri merupakan anak perusahaan dari PT. Pelindo III. Terminal Teluk Lamong dibangun untuk mengantisipasi over capacity di Pelabuhan Tanjung Perak, yang merupakan pelabuhan terbesar dan tersibuk kedua di Indonesia. Sehingga keberadaan dari PT. Terminal Teluk Lamong akan mengurangi kepadatan di jalur pelayaran dan mempercepat proses pengangkutan maupun distribusi barang.

Secara geografis, PT. Terminal Teluk Lamong berlokasi di bagian barat Pelabuhan Tanjung perak, tepatnya di kawasan perairan Teluk Lamong. Lokasi terminal ini sangat strategis karena berhubungan langsung dengan jalan raya, jalan tol Surabaya-Gresik.

PT. Terminal Teluk Lamong merupakan operator terminal berkonsep ramah lingkungan dan berteknologi semi otomatis. Terminal ini memiliki dua dermaga yaitu dermaga petikemas sepanjang 500 meter dan dermaga curah kering sepanjang 250 meter. Dalam pembangunannya, terminal ini direncanakan dengan kedalaman yang cukup yaitu 16 meter LWS (Low Water Spring) untuk menunjang kapal-kapal besar yang akan transit ke pelabuhan Indonesia. Ketersediaan dan kesiapan infrastruktur pelabuhan menjadi salah satu aspek penting dalam menarik minat kapal-kapal asing berukuran besar untuk transit di pelabuhan Indonesia. Hal tersebut dikarenakan sebelumnya kapal asing berukuran besar enggan bersandar di Pelabuhan Indonesia karena infrastruktur pelabuhan di Indonesia kurang memadai sehingga kapal asing berukuran besar lebih memilih transit di negara lain yang memiliki infrastruktur pelabuhan yang memadai.

Gudang CFS di PT. Terminal Teluk Lamong sekarang dimanfaatkan atau dialihfungsikan untuk kegiatan behandle. Kegiatan behandle merupakan kegiatan pemeriksaan terhadap peti kemas Import yang dicurigai oleh Bea Cukai. Ketika pemilik barang terkena SPJM (Surat Pemberitahuan Jalur Merah) maka peti kemas tersebut harus cek fisik atau behandle, kegiatan behandle ini dilakukan di area gudang CFS.

Pemeriksaan fisik tidak sepenuhnya dilakukan diarea gudang karena desain bangunan gudang yang tidak cocok untuk kegiatan pemeriksaan, sehingga kegiatan behandle dilakukan di luar area gudang dan baru memasukkan muatan ke dalam gudang dengan alat bantu forklift. Sehingga jika pemeriksaan dilakukan diluar banyak faktor yang menghambat kegiatan pemeriksaan peti kemas.

Optimalisasi Gudang CFS (Container Freight Station) PT. Terminal Teluk Lamong Surabaya untuk proses kegiatan behandle PT. Terminal Teluk Lamong merupakan perusahaan yang baru berdiri sejak 4 tahun yang lalu. Banyak kegiatan di dalam terminal yang masih berbenah demi memberikan pelayanan yang terbaik bagi pengguna jasa PT. Terminal Teluk Lamong.Tidak sedikit permasalahan yang timbul di lapangan ketika akan dan sedang melakukan pemeriksaan behandle di gudang CFS. CFS (Container Freight Station) adalah gudang tempat dimana dilakukan pengepakan atau pengkonsolidasian barang barang dengan partai kecil untuk dimasukkan kedalam peti kemas (stuffing) atau dikeluarkan dari peti kemas (stripping). PT. Terminal Teluk Lamong memiliki gudang CFS dengan total luas 5000 $\mathrm{m}^{2}$. 
Berdasarkan hasil wawancara yang sudah dilaksanakan dapat diketahui bahwa Occupation Ratio adalah perbandingan antara kapasitas dengan volume yang dioperasikan yang bertujuan untuk mengetahui tingkat kepadatan dan kondisi area apakah sudah mencukupi atau mememrlukan tambahan. Perbandingan kapasitas dengan volume masih dalam batas rasio yang normal, sebagai contoh kapasitas gudang bisa menampung 30 box container dan volume per hari hanya 25 box, dengan begitu occupation ratio yang digunakan masih dalam batas normal. Gudang CFS di PT. Terminal Teluk Lamong saat ini belum dapat menghitung Occupation Ratio karena CFS di Terminal Teluk Lamong belum digunakan untuk kegiatan penimbunan barang seperti fungsi CFS seharusnya. Gudang CFS baru sebatas difungsikan sebagai area behandle dan karantina.

Pemeriksaan fisik tidak sepenuhnya dilakukan diarea gudang karena desain bangunan gudang yang tidak cocok untuk kegiatan pemeriksaan, sehingga kegiatan behandle dilakukan di luar area gudang dan baru memasukkan muatan ke dalam gudang dengan alat bantu forklift.

Berikut merupakan alur proses kegiatan behandle di PT. Terminal Teluk Lamong:

a) Pengguna jasa melakukan job order kegiatan behandle secara online melalui web acces

b) Data akan masuk kedalam sistem $C$-Tos

c) Pengguna jasa mengkonfirmasi ke admin CFS

d) Admin CFS akan mengecek data job order

e) Pengguna jasa lapor pemeriksaaan ke loket bea cukai di dalam gudang CFS

f) Jika disetujui oleh bea cukai maka akan dilakukan proses stripping dan stuffing

g) Jika tidak disetujui maka pengguna jasa akan mengkonfirmasi ke customers service Terminal Teluk Lamong

h) Kemudian pengguna jasa akan melakukan job behandle ulang.

Pada kegiatan behandle yang dilakukan di gudang CFS PT. Terminal Teluk Lamong terdapat beberapa faktor yang menghambat kegiatan behandle yang terdiri dari Faktor Internal dan Eksternal, Faktor Internal merupakan faktor yang berasal dari dalam Terminal Teluk Lamong yang memengaruhi pelayanan kegiatan behandle baik dari sisi sumber daya manusia, peralatan, sistem aplikasi, dan sumber daya listrik. Faktor eksternal, berasal dari sisi luar terminal yang sangat memengaruhi pelayanan di dalam kegiatan behandle, antara lain kondisi barang didalam peti kemas, kesiapan perwakilan pemilik barang (ekspedisi muatan kapal laut) dalam mempersiapkan dokumen terkait dan kehadiran di terminal untuk menyaksikan kegiatan pemeriksaan fisik, sistem aplikasi dari stakeholder terkait (bea cukai dan karantina) maupun kondisi cuaca (hujan/angin) yang sangat berpengaruh saat pelayanan kegiatan behandle out door.

Kegiatan behandle yang memanfaatkan gudang CFS sebenarnya bisa dilakukan dengan catatan sarana dan prasarana yang memadai, dilihat dari uraian diatas masih banyak faktor yang memengaruhi kegiatan behandle. Sehingga terminal sebagai penyedia jasa fasilitas harus mempersiapkan seluruh sarana dan prasarana yang baik agar kegiatan behandle di PT. Terminal Teluk Lamong dapat berjalan dengan lancar.

Untuk itu Terminal Teluk Lamong dapat melakukan upaya dengan cara mempersiapkan sarana dan prasarana untuk kegiatan behandle:

a) Merenovasi gudang CFS untuk dibuatkan fasilitas longroom. Merenovasi Gudang CFS untuk dibuatkan fasilitas longroom untuk pemeriksaan peti kemas, sehingga seluruh kegiatan behandle bisa dilakukan diarea gudang CFS. Bangunan (long room inspection) memungkinkan dapat dilakukannya pengeluaran, pemeriksaan, dan pemasukan kembali barang yang dikeluarkan dari peti kemas.

b) Mempersiapkan darana pendukung untuk pemeriksaan fisik barang. Untuk memaksimalkan kegiatan behandle di PT. Terminal Teluk Lamong Surabaya maka perusahaan selaku penyedia jasa fasilitas dapat melakukan upaya penambahan alat agar kegiatan behandle dapat berjalan dengan baik, antara lain dengan cara penambahan peralatan untuk menunjang kegiatan behandle. Peralatan untuk mengangkat dan memindahkan barang dari dalam peti kemas seperti, forklift, hand fallet, dan trolley. Contohnya forklift, butuh penambahan forklift karena jika hanya tiga unit maka pemeriksaan behandle harus antri. 
Dengan penambahan forklift diharapkan tidak ada antrian untuk pemeriksaan dan juga mempercepat kegiatan stripping dan stuffing.

c) Mempersiapkan sumber daya manusia yang kompeten. Mempersiapkan sumber daya manusia atau tenaga kerja yang ahli dibidangnya sehingga dengan didukungnya alat bantu maka harus didukung juga dengan SDM yang berkompeten. Sehingga kegiatan behandle bisa dilakukan secara optimal di gudang CFS PT. Terminal Teluk Lamong.

\section{SIMPULAN}

Dari keseluruhan pembahasan yang telah dipaparkan maka kegiatan behandle yang dilakukan di gudang CFS PT. Terminal Teluk Lamong Surabaya dapat diambil simpulan, antara lain:

a) Kegiatan behandle di gudang CFS ternyata belum optimal karena pemeriksaan petikemas masih dilakukan di luar Gudang karena desain bangunan dari Gudang CFS belom sesuai dengan peruntukkannya. Fasilitas Gudang CFS dapat digunakan untuk menunjang proses behandle di PT. Terminal Teluk Lamong Surabaya. Akan tetapi pemeriksaan fisik tidak sepenuhnya dilakukan diarea gudang karena desain bangunan gudang yang tidak cocok untuk kegiatan pemeriksaan, sehingga kegiatan behandle dilakukan di luar area gudang dan baru memasukkan muatan ke dalam gudang dengan alat bantu forklift. Sehingga jika pemeriksaan dilakukan diluar banyak faktor yang menghambat kegiatan pemeriksaan peti kemas.

b) Faktor yang menghambat kegiatan behandle, adalah:

1) Faktor internal merupakan faktor yang berasal dari dalam Terminal Teluk Lamong yang mempengaruhi pelayanan behandle baik dari sisi sumber daya manusia, peralatan, sistem aplikasi, dan sumber daya listrik.

2) Faktor eksternal, berasal dari sisi luar terminal yang sangat memengaruhi pelayanan di dalam kegiatan behandle, antara lain kondisi barang didalam petikemas, kesiapan perwakilan pemilik barang (EMKL), sistem, petugas pemeriksa, dan kondisi cuaca
Berdasarkan simpulan dan pembahasan yang penulis uraikan diatas mengenai kegiatan behandle yang dilakukan di gudang CFS di PT. Terminal Teluk Lamong Surabaya, maka penulis menyampaikan saran yang dapat dijadikan sebagai bahan masukan, diantaranya:

a) PT. Terminal Teluk Lamong diharapkan dapat menyediakan tempat untuk kegiatan behandle agar kegiatan pemeriksaan peti kemas dapat berjalan dengan lancar.

b) PT. Terminal Teluk Lamong dapat memperbaiki sarana dan prasarana serta selalu berkoordinasi dengan EMKL, bea cukai, dan pihak-pihak terkait. Dan diharapkan dapat melalukan renovasi gudang, menyiapkan sarana pendukung pemeriksaan fisik barang, serta mempersiapkan SDM yang kompeten.

\section{DAFTAR PUSTAKA}

Arikunto, Suharsismi, 2010, Prosedur Penelitian Suatu Pendekatan Praktik, Rinerka Cipta, Jakarta.

Jonatan, Sarwono, 2006, Metode Penelitian Kuantitatif dan Kualitatif, Graha Ilmu, Yogyakarta.

Juliyansah Noor, 2016, Metode Penelitian, Skripsi, Tesis, Disertasi, dan Karya Ilmiah, Kencana, Jakarta

Keputusan Menteri Perhubungan, KM 11 Tahun 2007 tentang Pedoman Penetapan Tarif Pelayanan Jasa Bongkar Muat Peti Kemas.

Lambert, D.M., Stock, J.R., 2001, Strategic Logistic Manajement, Fourth Edition, Mc Graw Hill, New York - USA.

Sugiyono, 2013, Metodologi Penelitian Kuantitatif Kualitatif dan R \& D, Bandung.

Sugiyono, 2013, Metodologi Penelitian Pendidikan Pendekatan Kuantitatif, Kualitatif R\&D, Bandung.

Sugiyono, 2014, Metode Penelitian Dan Pengembangan, Bandung: Penerbit Alfabeta

Sukardi, 2013, Metodologi Penelitian Pendidikan Kompetensi dan Praktiknya, Bumi Aksara, Jakarta.

Suryosubroto, 2002, Proses Belajar Mengajar 
ISSN : 2087-3050

di Sekolah, PT. Rineka Cipta, Jakarta.

Sutrisno Hadi, 2015, Metodologi Riset, Pustaka Pelajar, Yogyakarta.

Zakiah Darajat, 2012, Fasilitas Transportasi Konsumen, CV. Alfabeta, Bandung.

http://www.teluklamong.co.id , 2013, diakses Maret 2020

https://kbbi.web.id/pengertian, 2016, diakses tanggal 5 Maret 2020 